\title{
Uraemic myoclonus: an example of reticular reflex myoclonus?
}

\author{
D. CHA D W ICK A N D A. T. FRE NCH \\ From Whipps Cross Hospital, Leytonstone, London
}

SUM MARY Two patients are described who developed action, reflex myoclonus during acute renal failure. In both cases the myoclonus was abolished after the intravenous administration of clonazepam. We suggest that the characteristic action myoclonus, which occurs in both acute renal failure and postanoxic encephalopathy, is caused by a disturbance of function in the lower brainstem reticular formation.

A number of abnormal movements may occur in patients with acute renal failure. These include muscle fasciculation, asterixis, and myoclonus (Locke et al., 1961; Tyler, 1968). There are, however, relatively few detailed clinical descriptions of uraemic myoclonus. Our purpose in this short communication is to describe the clinical characteristics of myoclonus in two patients with acute renal failure, and to report the dramatic effect of clonazepam in suppressing the myoclonus. These observations appear relevant to other recent observations in patients with myoclonus of different aetiologies (Chadwick et al., 1977), and may further our understanding of the basic mechanisms of some forms of myoclonus.

\section{Case reports}

CASE 1

A 69 year old man was admitted to hospital after a brief episode of uncontrollable shaking of his limbs without alteration of consciousness. For three weeks he had had backache and dysuria, which had been treated with cotrimoxazole and benorylate without effect. He had not passed urine for the 18 hours before admission.

For many years he had been hypertensive, adequately controlled by hydrochlorothiazide $12.5 \mathrm{mg}$, reserpine $62.5 \mu \mathrm{g}$, and potassium chloride $572 \mathrm{mg}$, one tablet (Salupres) daily. Nineteen months previously, bladder carcinoma had been diagnosed at cystoscopy, after an episode of haematuria. His-

Address for correspondence and reprint requests: Dr D. Chadwick, Department of Neurology, Royal Victoria Infirmary, Newcastle upon Tyne.

Accepted 10 July 1978 tology showed a transitional cell papilloma with infiltration of the lamina propria. This was treated by transurethral resection, and three subsequent cystoscopies had shown no evidence of recurrence. The indices of renal function had been normal until two months before admission, when plasma urea was $10.1 \mathrm{mmol} / \mathrm{l}$ and creatinine $139 \mu \mathrm{mol} / \mathrm{l}$.

On admission he was obviously unwell, but apyrexial. The jugular venous pressure was raised $30 \mathrm{~mm}$ above normal, and his blood pressure was $220 / 120 \mathrm{mmHg}$. There were no palpable abdominal masses but per rectum there was a hard fixed mass, proximal to the prostate, extending bilaterally into the pelvis. He was fully conscious, and orientated in time and space. There was no asterixis, but he exhibited a variety of rapid, brief involuntary movements. At rest there were frequent, but irregular, fascicular muscular contractions. When these affected proximal muscles no movement resulted, but when they involved distal limb muscles, fine movements of fingers and toes occurred. Any disturbance, however, precipitated more gross muscle jerking, affecting either a single limb or, more frequently, the head, trunk, and all four limbs synchronously. Such myoclonus was at times sufficiently violent to be a danger to the patient and his attendants. A number of stimuli were effective in precipitating such myoclonus. The most potent of these was attempted voluntary movement. Passive movement of a limb, eliciting tendon reflexes, and rapid stretch stimuli applied to the fingers, also resulted in myoclonus which was sometimes restricted to the limb stimulated but more often involved the whole body. Sudden auditory stimuli evoked generalised myoclonus, but tactile (without joint displacement) and photic stimuli did not. There were no abnormal cranial 
nerve signs. Muscle tone and power were normal, but co-ordination was grossly impaired because of myoclonus. Sensation was normal and tendon reflexes normally reactive. Plantar responses were flexor.

At admission investigations showed a haemoglobin of $13.3 \mathrm{~g} / \mathrm{dl}$, white cell count of $8.2 \times 10^{9} / 1$, and an ESR of $66 \mathrm{~mm}$ in the first hour. The plasma urea was $34.6 \mathrm{mmol} / \mathrm{l}$, creatinine $1188 \mu \mathrm{mol} / \mathrm{l}$, sodium $144 \mathrm{mmol} / 1$, potassium $5.8 \mathrm{mmol} / 1$, chloride $109 \mathrm{mmol} / \mathrm{l}$, and bicarbonate $15 \mathrm{mmol} / \mathrm{l}$. Results of serum calcium and phosphate, blood sugar, and liver function tests were all normal. The ECG showed peaked $\mathrm{T}$ waves compatible with hyperkalaemia, and the chest radiograph showed upper lobe blood diversion. A high dose intravenous urogram demonstrated an enlarged right kidney with dilated calyces. The left kidney was of normal size but the calyces were not clearly visualised.

A diagnosis of acute obstructive renal failure was made, and peritoneal dialysis started. His involuntary movements ceased over 24 hours with the fall in plasma urea and creatinine. Subsequent cystoscopy showed the bladder to be oedematous and deformed by a posterior mass. Exploratory laparotomy revealed a tense right kidney and retroperitoneal tumour invading the pelvis with involvement of para-aortic lymph nodes. Histology showed moderately differentiated transitional cell carcinoma.

Dialysis was terminated, and over the subsequent two days he developed an identical pattern of involuntary movements to that described previously, as his blood urea rose from 16.9 to 25.3 $\mathrm{mmol} / \mathrm{l}$. He died three days after laparotomy.

\section{Effect of clonazepam}

On admission the patient's myoclonus was of such violence as to make the insertion of a peritoneal dialysing cannula impossible. However, a $1 \mathrm{mg}$ intravenous bolus of clonazepam abolished the myoclonus, allowing insertion of the cannula under local anaesthesia. Voluntary movement and previously effective sensory stimuli no longer evoked myoclonus, although some small fascicular muscle contractions were still present. When the myoclonus returned after stopping dialysis, there was a similar response to further clonazepam intravenously. Intravenous saline in an equivalent volume was without effect. A single $1 \mathrm{mg}$ bolus of clonazepam relieved myoclonus for up to four hours.

CASE 2

A 55 year old man, with no preceding relevant medical history, was admitted to the intensive therapy unit with a two week history of sore throat, cough, malaise, and fever.

$\mathrm{He}$ was plethoric, hyperventilating, and had multiple areas of skin infarction over the arms and the legs. He was hypotensive $(90 / 70 \mathrm{mmHg})$ with a sinus tachycardia of $140 /$ minute. There was a long midsystolic murmur (grade 2/6) audible at the left sternal edge but his chest was clinically clear and his abdomen normal to palpation. He was drowsy but orientated in time and space. There was no neck stiffness, and his fundi were normal. There were no localising neurological signs.

At admission his haemoglobin was $14.2 \mathrm{~g} / \mathrm{dl}$, white cell count $14.1 \times 10^{\circ} / 1$ ( $82 \%$ neutrophils), platelets $15000 \times 10^{9} / 1$, and ESR $70 \mathrm{~mm}$ in the first hour. Clotting factors were normal, as was a CSF examination. The chest radiograph showed a slightly increased cardiothoracic diameter, but was otherwise unremarkable. A midstream specimen of urine was sterile but contained $50-100$ red cells/ $\mu 1$. An initial blood culture yielded a growth of Staphylococcus albus, but a throat swab produced a heavy growth of $\beta$-haemolytic (Lancefield Group A) streptococci. Liver function tests and a bone marrow examination were normal.

A diagnosis of bacterial endocarditis was made, and treatment was started with intravenous benzyl penicillin ( $4 \mathrm{~g}$, four hourly), methicillin ( $1 \mathrm{~g}$, four hourly), and cephalothin ( $1 \mathrm{~g}$, four hourly). However, his condition deteriorated, and he became oliguric. On admission his plasma urea was 19.4 $\mathrm{mmol} / \mathrm{l}$, creatinine $244 \mu \mathrm{mol} / 1$, sodium $126 \mathrm{mmol} /$ 1, potassium $3.7 \mathrm{mmol} / 1$, bicarbonate $15 \mathrm{mmol} / 1$, and chloride $92 \mathrm{mmol} / \mathrm{l}$. Over three days his plasma urea rose to $42 \mathrm{mmol} / \mathrm{l}$ and creatinine to $424 \mu \mathrm{mol} / 1$. At this time he developed myoclonus.

He was by then stuporose and confused. There were no abnormal movements at rest, but any voluntary movement precipitated myoclonus. It could also be evoked by passive movement, stretch stimuli applied to the fingers, and eliciting tendon reflexes. There was no clinical myoclonic response to auditory or photic stimuli. The myoclonus usually involved both proximal and distal limb muscles in the limb moved or stimulated. No truncal myoclonus was seen, and only on rare occasions did the response to movement or sensory stimuli involve more than one limb.

The myoclonus persisted for 48 hours, except when suppressed by clonazepam (see below). After this, deteriorating renal and respiratory function required peritoneal dialysis and intermittent positive pressure ventilation. He died 14 days after admission. Postmortem examination confirmed the presence of bacterial endocarditis with some Gram positive cocci within vegetations on the mitral valve. The brain and kidneys were macroscopically normal. 


\section{Effect of clonazepam}

The administration of $0.75 \mathrm{mg}$ of clonazepam as an intravenous bolus abolished the myoclonus in the patient from one minute to five hours after injection. Injection of diluent and an appropriate amount of saline was without effect.

\section{Discussion}

The myoclonus which occurred in both these patients with acute renal failure was clinically similar to the action or intention myoclonus described by Wolfhart and Hook (1951) and Lance and Adams (1963) in syndromes of different aetiology - that is, it was usually absent when the patient was at rest, but was provoked by any voluntary movement. Lance and Adams (1963) also demonstrated that a variety of sensory stimuli were capable of provoking a myoclonic response in their patients with postanoxic encephalopathy. Most potent of these were proprioceptive and sudden auditory stimuli. The same was true of these uraemic patients.

Our understanding of the basic mechanisms of such action myoclonus has been advanced by recent physiological, pharmacological, and biochemical observations in patients with postanoxic myoclonus (Chadwick et al., 1977; Hallett et al., 1977). It now seems possible to identify a group of such patients in whom (a) myoclonus frequently involves proximal limb and truncal muscles; (b) the myoclonic response to peripheral proprioreceptive stimuli involves not only the distal muscles of the limb to which the stimulus is applied, but also proximal muscles of that limb and of ten the muscles of other limbs; (c) the EEG shows spike or polyspike and slow wave activity which bears a variable temporal relationship to the muscle action potential associated with the myoclonic jerk; (d) the cortical somatosensory evoked responses to electrical stimulation of the median nerves are not enlarged; (e) during a generalised myoclonic jerk; brainstem nuclei appear to be activated in an ascending order; and (f) the myoclonus is alleviated dramatically by the administration of either serotonin precursors or clonazepam. In such patients the myoclonus may be mediated by a spinobulbarspinal reflex, which, under normal circumstances, is inhibited by serotonergic neural systems (Chadwick et al., 1977). The term "reticular-reflex myoclonus" has been used to describe this phenonemon (Hallett et al., 1977).

There appear to be several similarities between reticular reflex, postanoxic myoclonus, and the myoclonus in these uraemic patients. In the latter, proximal muscle groups were frequently involved in the myoclonic response to voluntary movement, and sensory stimuli could evoke a generalised myoclonic response in one case. We were unable to make electrophysiological observations on our patients but Tyler (1968) described paroxysmal slow wave, and spike and slow wave activity occurring in the EEG of uraemic patients. He does not, however, comment on its relationship to myoclonus. While we know of no data on the effect of renal failure on the somatosensory evoked response, or the direction of activation of brainstem structures in uraemic myoclonus, clonazepam is dramatically effective in suppressing both uraemic and reticular reflex, postanoxic myoclonus (Chadwick et al., 1977).

Further study is necessary before firm conclusions can be drawn, but it seems probable that both uraemia and anoxia cause myoclonus mediated by similar mechanisms. Indirect evidence from electrophysiological studies in postanoxic patients suggests that the lower brainstem reticular formation is actively involved (Hallet et al., 1977). However, no animal model of postanoxic myoclonus exists, and this makes direct testing of this hypothesis impossible. It is, therefore, of interest that infusions of urea cause myoclonus in cats.

Zuckerman and Glaser (1972) noted that, during the continuous infusion of urea, cats initially developed asynchronous fascicular muscle twitching, which gradually increased in magnitude, tended to become synchronised, and merged into clear-cut localised myoclonic jerks. Loud noises, proprioceptive stimuli, and voluntary movement evoked generalised myoclonus. The myoclonus in this model thus appears identical to that occurring in the clinical setting. Detailed electrophysiological studies in the cat showed that supramesencephalic structures were not involved in the production of the myoclonus which appeared to be related to paroxysmal activity in the lower brainstem reticular formation, in particular in the nucleus gigantocellularis. This depended to a large extent on a sensory input, as cervical cord section and curarisation both reduced, but did not completely abolish, the paroxysmal activity during urea infusion.

We would, therefore, suggest that the characteristic action myoclonus, which occurs in both acute renal failure and postanoxic encephalopathy is caused by disturbance of function in the lower brainstem reticular formation. This results in the abnormal reflex responses to sensory stimuli which constitute this form of myoclonus. 
We are grateful to Dr G. C. Hanson and Dr P. L. Wright for permission to report their patients, and to Professor C. D. Marsden for his criticism and advice.

\section{References}

Chadwick, D, Hallett, M., Harris, R., Jenner, P., Reynolds, E. H., and Marsden, C. D. (1977). Clinical, biochemical and physiological factors distinguishing myoclonus responsive to 5-hydroxytryptophan, tryptophan plus a monoamine oxidase inhibitor, and clonazepam. Brain, 100, 455-487.

Hallett, M., Chadwick, D., Adam, J., and Marsden, C. D. (1977). Reticular reflex myoclonus: a physiological type of human post-anoxic myoclonus. Journal of Neurology, Neurosurgery, and Psychiatry, 40, 253-264.
Lance, J. W., and Adams, R. D. (1963). The syndrome of intention or action myoclonus as a sequel to hypoxic encephalopathy. Brain, 86, 111-136.

Locke, S., Merrill, J. P., and Tyler, H. R. (1961). Neurological complications of acute uremia. Archives of Internal Medicine, 108, 519-530.

Tyler, H. R. (1968). Neurological disorders in renal failure. American Journal of Medicine, 44, 734-748.

Wolfhart, G., and Hook, O. (1951). A clinical analysis of myoclonus epilepsy (Unverricht-Lundborg) myoclonic cerebellar dyssynergy (Hunt) and hepatolenticular degeneration (Wilson). Acta Psychiatrica Scandinavica, 26, 219-245.

Zuckerman, E. G., and Glaser, G. H. (1972). Ureainduced myoclonic seizures. Archives of Neurology (Chicago), 27, 15-27. 